\title{
Development of process indicators for coastal zone management assessment in France
}

\author{
Yves Henocque * \\ Institut Français de Recherche pour l'Exploitation de la MER (IFREMER), B.P.330, 83507 La Seyne sur Mer, \\ Cedex, France \\ * : Tel: +33-4-9430-4907; fax: +33-4-9406-5529 ; E-mail address: yves.henocque@ifremer.fr
}

\begin{abstract}
:
In order to assess local experiences of coastal management in France and their use of existing planning instruments, five case studies (Iroise Sea, Bay of Brest, Charentais Sounds, Morbihan Gulf, Bay of Arcachon) were selected along the French Atlantic coast for their geographic representativity, the issues at stake, and the coastal planning instruments under use. After a short description of their main characteristics, it is shown how a common grid of analysis has been settled and applied to the five case studies, with a focus on the definition and valuation of meaningful integrated coastal management (ICM) process indicators. The results lead to a clear identification of the strengths and weaknesses of available planning tools and their necessary adaptation to future ICM strategies at the local and national levels, in the framework of the recent European recommendation on ICZM. From the active application of such indicators, it is proposed to develop a "Good Practice Guide" which would be beneficial to ICM initiatives on the French coast and elsewhere.
\end{abstract}

Keywords: local level, planning tools, process indicators, integrated management 


\section{Introduction}

Like in most European countries, the institutional framework for coastal zone management in France is comprised of two elements : a land use planning system administered by territorial authorities at one or more sub-national territorial levels, and sectoral laws which are usually reflected in sectoral administrations within the national government. Specific policy for coastal areas is provided for under the Coastal Development, Protection and Enhancement Act (1986) known as the Coast Act, mainly devoted to land use planning for control of urban expansion in coastal areas. Planning instruments established under the Coast Act and other laws (Water Act, 1992 ; Spatial Planning and Development Act, 1995) such as the Marine Area Zoning Plans (SMVM), the Regional Nature Park (PNR), the Bay Contracts, or the Territorial Planning Directives (DTA), represent for the local decision-maker a complex combination of broad rules at different scales and quite cumbersome administrative procedures that do not facilitate the setting up of a coherent and integrated coastal zone management approach. No local planning tool prevails for the implementation of integrated coastal zone management, but where there is a real dynamic between local stakeholders with a strong leadership, partnership agreements are combined with regulatory and highly centralised planning instruments like the Marine Area Zoning Plan. Capacity building for integrated coastal zone management is just beginning and is starting to happening first at the local level.

In order to assess these local experiences and how they make use of the existing planning instruments, a Coastal Environment Commission was named and settled by the government in 2001. This Commission was composed of 18 members, representatives from ministries, government agencies, regions and universities, assisted by three CZM experts. It was chaired by IFREMER President, the main French marine sciences R\&D agency. In a first approach, five case studies were selected on the Atlantic coast and their coastal zone management processes assessed through a common set of process indicators. The Commission work lasted about one year, from June 2001 to May 2002.

\section{Background to assessment of ICM process}

For the purpose of the Coastal Environment Commission (CEC) work, Integrated Coastal Management (ICM) process was considered with reference to the GESAMP [1] definition:

"A continuous and dynamic process that unites government and the community, science and management, sectoral and public interests in preparing and implementing an integrated plan for the protection and development of the coastal ecosystem and resources".

ICM is thus defined as being an iterative and collective process which must be coordinated using a multidisciplinary, multi-tool approach, according to a non-linear time scale. Measuring effectively the status of any ICM programme or project is therefore a complicated task which requires the need for new development paradigms that are built from tested and innovated approaches, and a performance monitoring system designed specifically to measure the impacts of these approaches.

One of these new paradigms which have been used by CEC as criteria is the ICM policy cycle framework and the orders of outcomes proposed and tested by Olsen [2], "in a manner that can set the stage of comparisons across bodies of experience".

This approach and others have been pulled together during an important workshop on across portfolio learning in ICM held on Block Island (Rhode Island, USA) in 2001. This workshop outcomes have been particularly important in defining how better document and analyse ICM 
experiences in order to better understand what works, what doesn't and why in a diversity of contexts. Its recommendations have then been reviewed and integrated by the $\mathrm{RIO}+10$ working group on ICM in Paris (IOC, December 2001).

In Europe, the European Environment Agency (EEA) is currently developing indicators based on the DPSIR (Driving Force, Pressures, State, Impact, Responses) assessment framework in compliance with its duty of reporting on the main European water policies, i.e. the Water Framework Directive, Nitrate Directive, Urban Waste Water Treatment Directive, Common Fisheries Policy, the Marine Conventions and their Action Plans (OSPAR, HELCOM, UNEP/MAP, AMAP, BSEP), and its Recommendation on Integrated Coastal Area Management. Since this latter policy is just in its infancy in Europe, there is not yet an operational system of indicators for a cross-assessment of national or local experiences in ICM between member-countries (EEA [3]).

\section{Review, analysis, collation and integration of information}

Five case studies (Iroise Sea, Bay of Brest, Charentais Sounds, Morbihan Gulf, Bay of Arcachon) have been selected along the French Atlantic coast following three criteria : representative sites of the main western coastal regions, sites covering a significant range of issues, and using a large spectrum of different ICM tools.

In the absence of any specific national ICM framework, there is no so-called ICM project under development on these sites but several initiatives linked to different planning instruments, whether decentralised (Regional Nature Park-PNR, Territorial Planning Directives-DTA, Water Management Plan-SAGE, etc.) or centralised (Marine Area Zoning Plan-SMVM, National Park, Sanctuaries, etc.) in nature. It is from these different experiences, through the combination of existing planning instruments and the increasing awareness of their limit in regard of the sustainable development of the coast, that the ICM approach is finding its way in local decision-making practices.

The Iroise Sea area, in the western end of Brittany, has an archipelago of small islands already protected as natural sanctuary. There are about 1,500 islanders, 500 fishermen, and a total of 90,000 inhabitants along its coast. Following several years of scientific research and local institutional cooperation, the State decided that it was worth protecting the whole sea area taking into account the many uses and especially the fisheries activity. Through the settling of a local steering committee, a feasibility study for establishing a multi-use National Park for the whole area (200,000 ha) was submitted to the main stakeholders. This project is currently under discussion since its implementation would not only required the stakeholders' adhesion but the State amendment of National Park legislation too.

The Bay of Brest is opened to the Iroise Sea. The bay and its watershed cover a superficy of $2,800 \mathrm{~km}^{2}$ (of which only $180 \mathrm{~km}^{2}$ concern the bay itself). This area gathers 137 municipalities from three Départements (equivalent to counties) with about 360,000 inhabitants. It is a rather rural region with intensive agriculture and farm-produce industry (cows, porks) while crops are almost exclusively dedicated to cattle feeding. The Bay of Brest also shelters an important civil harbor and the French navy for the Atlantic coast. Within the bay, fishing is not that important but scallop fishing is emblematic and part of the local cultural heritage, as well as oyster and mussel farming. To respond to an increasing pressure and impacts regarding the bay water quality, a Bay Contract was prepared (1992-1998) by the Brest Urban Community (intermunicipalities group) and officially adopted by the State in 
1998. In the meantime, the Bay of Brest and its catchment area were selected as one of the European Union demonstration site for ICZM (1996-1999).

The Charentais Sounds are located on the southwestern coast of France, just in the North of the Gironde river. They are formed in between two islands (Ré and Oléron) and the maincoast and comprise two sounds called Breton and Antioche and a famous bay called MarennesOleron. They are highly productive areas which make them the first oysters and mussels rearing areas. As early as 1985, the Marennes Oleron Bay was considered as overstocked by a 100,000 tons of cultured oysters deployed over 3,600 ha of leasing grounds, 23,000 tons of wild oysters, and more than 50,000 tons of benthic filter feeders, leading to a significant oyster growth rate and resulting economic yield declines. Meanwhile, increased river uptaking and ground draining for agriculture development have considerably affected the primary productivity in coastal waters and their quality (micropollutants), leading to management conflicts between activities. It was thus decided by the State (Prefet) and the municipalities to start a procedure for establishing a Marine Area Zoning Plan (SMVM) which has been under debate till now.

The Morbihan Gulf is located in South Brittany, in the North of the Loire river. It is a close seawater body (11,500 ha) with a very rich and complicated pattern of small islands and peninsulas. Because of its attractiveness, the population growth reached $30 \%$ in the last 20 years (150,000 inhabitants in 2002) without mentioning about 700,000 visitors a year, mainly during the warm season. A pre-existing intermunicipalities structure for the development of the Gulf started to move in 1994 along three main goals : (1) Coordination of uses in the gulf and on the shoreline; (2) The gulf waters quality and partnership with agriculture development; (3) Landscapes enhancement. The new coordination structure comprises 38 municipalities covering 75,400 ha $(+11,500$ ha for the marine area). After a good deal of local concertation with the different stakeholders, it was decided to prepare a Regional Nature Park, a charter between local partners to reconcile economic development and environemental protection. This project is supposed to be ready (the charter and its action plan) by 2003. In the meantime, the State decided (1997) to launch a Marine Area Zoning Plan (SMVM), integrating sites under the European "Natura 2000" network and the Ramsar Convention.

The last one, the Bay of Arcachon, is located on the southwestern Atlantic coast, close to the city of Bordeaux. Like the previous site (Morbihan Gulf), population growth is relatively high (42,000 to 100,000 inhabitants between 1936 and 2000), with about 500,000 visitors a year. The area is another important production area for oysters but also, most importantly, for providing oyster seedlings to most of the French coast producing areas. To date, no evidence suggests that biomas in the bay (some 35,000 tons) may exceed its biotic capacity, but the proliferation of wild oyster populations and other competitors must be closely watched. Besides, on several occasions the bay has proved sensitive to pollution from various sources like nutrients from agriculture activity or micropollutants from ports dredging. Land development and town planning schemes have to be consistent with the maintenance of an healthy oyster production activity and hence healthy waters. Yet, an intermunicipalities coordinating structure has been working on sewage collecting network all around the bay (900 $\mathrm{km}$ of pipes) and water treatment plants installation for 40 years. The procedure for the definition of a Marine Area Zoning Plan (SMVM) then started in 1994 and is currently under examination by the State.

From this presentation, one can identify one or two main issues/objectives for each of the case studies : 
- Iroise Sea : Environmental protection in a multi-use large marine ecosystem (institutional instrument concerned : National Park).

- Bay of Brest : Control of pollutants runoff and pollution reduction in the coastal zone (institutional instrument and project concerned : Bay Contract, demonstration site within the European ICM programme).

- Pertuis-Charentais : Catchment water management and control of freshwater runoff into the coastal zone (institutional instruments concerned : SMVM, SAGE).

- Morbihan Gulf : Urban sprawling and impacts on the coastal zone (institutional instruments concerned : Regional Nature Park, SMVM, Natura 2000, Ramsar site)

- Bay of Arcachon : Urban sprawling and leisure ports dredging (institutional instruments and project concerned : SMVM, Regional Nature Park, SAGE, demonstration site within the European ICM programme).

For the Commission it was clear that its analysis should be related to what happens on the entire area in relation with the issues and objectives mentioned above, whatever the nature and the number of planning instruments developed on that area. Therefore, the ICM process analysis is not necessarily limited to one specific project but rather considers the different existing initiatives which contribute to ICM development on a given territory.

\section{Defining meaningful process indicators}

Far from judging each case study results, the Commission's main objective was through them to analyse the integrated coastal management processes at work, their strength and weaknesses. Since the time strictly devoted to the Commission work was limited due to its members regular activity, the approach was the following :

- review of existing sources (projects history, issues at stake, decision-making process and type of agreements between actors, legislative framework and institutional instruments);

- one day auditing by site consisting in meeting 5 key persons in the ICM process (State, local government or NGO representatives) with a large participation from other stakeholders (about 50 persons a meeting);

- information, discussion and synthesis sessions between Commission members.

In order to get the Commission members with the same level of information and make them use the same language about the ICM approach, a preliminary presentation of the ICM framework (definition, main principles, processes) and examples of achievements in the world was made at the intention of the Commission members. Among the utilized sources was the recent guidebook on ICM edited by IOC-UNESCO [4] with the collaboration of IFREMER.

In order to structure the auditing session and then make a comparative analysis, the Commission members first developed a questionnaire which was divided in 7 parts or 7 ICM processes :

1) What is at stake and what are the objectives regarding the environmental status (including environmental crisis) and the socio-economic activities in the different agreements concerning the management of the area? Did these stakes and objectives change within the process? To what scenario and time-scale do they relate? Are they prioritised? Are they part of an agreement?

2) Who are the actors within the process ? What is the respective role of the State (key ministries and their technical agencies), the local authorities, the local stakeholders, 
and what have been the institutional arrangements through the successive ICM steps? Who did not participate?

3) What are the tools which have been used during the ICM process ? How the sectoral tools have been used and articulated through the successive steps ? What is the role and utility of administrative and legislative tools ? What are their pros and cons if single used or in a complementary way?

4) What are the different knowledge frameworks used in the process? Were they already there or was it necessary to implement additional studies and integrate their data? What have they been used for and did they lead to some exchanges of information with other projects? What are the loopholes?

5) What are the outcomes, in terms of results (better decision-making, participation, awareness, behaviour changes, etc.) and products (marine park, bay contract, SMVM)? Do they fit to the objectives ?

6) How is the contract implemented ? Is the result satisfying, useful or operational ? Are follow-up tools available and what is the indicators system under use ? What kind of evaluation is implemented and initial objectives are they precise enough to allow such an evaluation?

7) What are the adaptive mechanisms in terms of prospective and objectives, in relation with the effective results, new constraints or externalities ? Are these mechanisms actually existing or forecasted ? Is adaptation felt already as a necessity?

These questions represented the starting point for defining 7 respective process indices and their indicators as follows :

1. Relevance Index (Stakes vs. Objectives)

2. Actors / Institutional arrangements Index

3. Use and integration of tools Index

4. Information and communication Index

5. Outcomes Index

6. Follow-up and evaluation Index

7. Adaptation and sustainability Index

To each index corresponds a set of indicators, themselves described through a series of detailed questions (Annex 1). Each of these indicators receives a value ranked between 1 and 3 (low / medium / high) and the index value will correspond to the mean value of each set of indicators, thus between 1 and 3 , too. In order to facilitate the successive comparative analysis, it was decided to set up a grid presenting the indices (vertical) and the five case studies (Tables 1 and 2). To allow a better evaluation, the analysis was carried out through a two steps approach, the first one concerning the two indices considered as key (Relevance and Outcomes Indices) plus a new one called "Prospective Index", indicating the necessity of change in a non conservative scenario. The second step, which includes the other indices, gives more insight in the different processes involved hence explaining further the index values observed in the first step (Relevance, Outcomes and Prospective indices).

For the exercise testing and thus significance, it was asked to several members of the Commission to independently make the exercise, attributing values to each indicator and index. Whilst each one's training background is quite different, the respective results were close enough to consider there was a good consensus within the group provided their information level about the case studies was similar. The values have then been gathered and discussed one by one to come up with the following results and discussion. 


\section{Results presentation and discussion}

Table 1 : Case studies process indices mean values - Step 1

\begin{tabular}{|c|c|l|c|c|c|}
\hline Case studies & Iroise Sea & $\begin{array}{l}\text { Bay of } \\
\text { Brest } \\
\text { Processes }\end{array}$ & $\begin{array}{c}\text { Pertuis } \\
\text { Charentais }\end{array}$ & $\begin{array}{c}\text { Gulf of } \\
\text { Morbihan }\end{array}$ & $\begin{array}{c}\text { Bay of } \\
\text { Arcachon }\end{array}$ \\
$\begin{array}{c}\text {-1- } \\
\text { Relevance Index } \\
\text { (Stakes/Objectives) }\end{array}$ & 2,4 & 2,6 & 1,5 & 2,4 & 2,4 \\
\hline $\begin{array}{c}\text {-5- } \\
\text { Outcomes Index } \\
\text { (Results/Products) }\end{array}$ & - & $\begin{array}{l}\text { Ordre I } \\
\text { (II et III } \\
\text { Partiels) }\end{array}$ & $\begin{array}{l}\text { Ordre II } \\
\text { (partiel) }\end{array}$ & $\begin{array}{l}\text { Ordre I } \\
\text { (Ordre II } \\
\text { partiel) }\end{array}$ & $\begin{array}{l}\text { Ordre I } \\
\text { (Ordres II } \\
\text { et III partiels) }\end{array}$ \\
\hline $\begin{array}{c}\text { Prospectice Index } \\
\text { (Scenario/Change) }\end{array}$ & 1,5 & 2 & 1 & 2,5 & 2,5 \\
\hline
\end{tabular}

Table 2: Case studies process indices mean values - Step 2

\begin{tabular}{|c|c|c|c|c|c|c|}
\hline Processes & $\begin{array}{l}\text { Iroise Sea } \\
\text { Relevance: } 2,4 \\
\text { Prospective: } 1,5\end{array}$ & $\begin{array}{l}\text { Bay of Brest } \\
\text { Relevance: 2,6 } \\
\text { Prospective: } 2\end{array}$ & $\begin{array}{l}\text { Pertuis } \\
\text { Charentais } \\
\text { Relevance: } 1,5 \\
\text { Prospective: } 1\end{array}$ & $\begin{array}{l}\text { Gulf of } \\
\text { Morbihan } \\
\text { Relevance: } 2,4 \\
\text { Prospective: 2,5 }\end{array}$ & $\begin{array}{c}\text { Bay of } \\
\text { Arcachon } \\
\text { Relevance: } 2,4 \\
\text { Prospective: } 2,5\end{array}$ & $\begin{array}{l}\text { Mean } \\
\text { value }\end{array}$ \\
\hline $\begin{array}{c}-2- \\
\text { Actors/Institutional } \\
\text { arrangements }\end{array}$ & 2 & 2,2 & 1,6 & 2,5 & 2,4 & 2,1 \\
\hline $\begin{array}{c}-3- \\
\begin{array}{c}\text { Use/Integration } \\
\text { of tools }\end{array} \\
\end{array}$ & 1,5 & 1,9 & 1,5 & 2 & 1,9 & 1,8 \\
\hline $\begin{array}{c}-4- \\
\text { Information// } \\
\text { communication }\end{array}$ & 1,6 & 2,3 & 1,8 & 1,8 & 2,4 & 2 \\
\hline $\begin{array}{c}-6- \\
\text { Follow-up/ } \\
\text { evaluation }\end{array}$ & 1,2 & 1,9 & 1,2 & 1,5 & 1,6 & 1,5 \\
\hline $\begin{array}{c}-7- \\
\text { Adaptation / } \\
\text { sustainability } \\
\end{array}$ & 1 & 2,3 & 1,5 & 1,8 & 2 & 1,7 \\
\hline
\end{tabular}

$\underline{\text { Step } 1}$

The Relevance index value is generally good, except in the case of Pertuis Charentais. For this latter, although numerous studies were achieved, there is still a strong debate about the boundaries of the SMVM area and its coordination with the other planning instruments in order to allow a thorough consideration of the main issue which is related to water management (agriculture) and freshwater runoff into the coastal waters (shellfish farming and fisheries). There is still a split between planning tools devoted to marine waters and those dealing with the watershed, rending the overall vision of the coastal zone as an interface between land and sea still difficult to achieve. 
The Outcomes index is characterized by very partial results due to the fact that the examined case studies, although at various stages, are still in their initial phase. Order I results (action plan, institutional arrangement, financing) are the most common while Order II results (behaviour changes, first actions) are more evenly shown. There are no Order III results (environmental or socio-economic improvements) except where long term sectoral policies allow tangible results like scallop restocking in the bay of Brest or water quality in the bay of Arcachon. Generally speaking, all the sites have benefited from well-funded and long term (20 years) programmes for sewage collecting and treatment in regard of their coastal waters quality. It is worth noting that this distinction between orders of result give local decisionmakers quite a new insight in term of coherence when looking backward at what they have achieved.

The Prospective index is weaker. If sustainable development is getting a rather familiar concept, it is not yet the case with the ICM adaptive approach. People were used to long term top-down planning instruments tolerating a few changes in the initial objectives. While most of the projects are in a planning phase, potentialities of ruptures or of re-orientation have been evidenced. These potentialities can be detailed further in step 2 with questions like : do we have to include other stakeholders ? Did we optimise the use of the different tools ? Did we communicate enough ? Are we capable enough to measure the project outcomes ? The level of prospective indices is also related to the planning instruments diversity (legislative framework, administrative procedure, funding mechanism, etc.) on a same territory and thus the lack of visibility for local actors. There is clearly a need for an integrating framework to make these different planning mechanisms more coherent.

\section{$\underline{\text { Step } 2}$}

Actors and institutional arrangements index : the index mean value is noticeably attributable to new practices of participation (practice often named under the "participative democracy” concept) from the State, the local authorities, the NGOs and local users, following the process of "learning by doing". In this process, there are still loopholes in the setting and running of representative steering committees, their working groups thematic (in regard of the objectives) and composition, and there is a lack of legitimate leaders who could act as facilitators within the ICM process. The various initiatives taking place within a same territory, in the framework of different planning instruments (ex: SMVM as a zoning and regulatory document applied to the coastal strip under the State initiative / Regional Nature Park as a non-binding document, more partnership-like, under the local authorities initiative), should have a coordinating mechanism.

Use and integration of tools index : values are relatively low. Observation tools like monitoring networks and their information system (e.g. GIS, models) are there but socioeconomic approaches are rather weak, as regard for example the assessment of ecosystem value and the use of cost-benefit analysis for elaborating prospective scenarios. Legislative and institutional considerations are also poorly mentioned in the diagnostic documents. Since each sectoral administration uses its own tools and procedures, it is rather difficult for the local stakeholders to have a good overview of what happens on its own territory. Economic incentives tools, quite developed in some sectors (e.g. water management), should be more integrated in the planning documents and their action plans. It is worth mentioning the increasing use of voluntary agreements between specific groups of actors (e.g. agriculture / shellfish farming for water management), sometimes encouraged by the State. 
Information and communication index : the values vary but keep close to the mean value. Important data banks and well-developed information system usually allow the editing of rather comprehensive thematic mapping in relation with issues and their corresponding objectives. This information is largely based on scientific and technical studies where local knowledge is poorly used, a situation which does not promote the sense of ownership from local users. The means and way of communicating on the diagnostic documents and on the ICM process (more specifically the feedback process) as a whole are still rather administrative although nowadays local authorities (inter-municipalities structures) tend to promote participation through interviews, workshops, forum, etc. This situation will thus improve with information accessibility and development of a common language for better sharing between vested interests.

Follow-up and evaluation index : the index is generally weak. Indicators system are usually poorly developed. There is a common view there is no need to develop them right from the beginning of the project preparation phase but only at the end of the planning process. Poor identification of indicators is then directly linked to the lack of objectives quantification, in time and scale, with the project unfolding. As usual, some environmental improvements indicators are defined as regard the expected final results (10 or 15 years in the case of SMVM) but there is no reference to more tangible intermediate results like behaviour changes or institutional mechanisms. Still, evaluation is not considered as an internal, learning approach, but merely as a control procedure coming from the outside. Funding mechanisms are scattered within the different existing initiatives in a same area. Again, their coordination within an overall action plan for the whole area should greatly add to their effectiveness in supporting a coherent set of management activities.

Adaptation and sustainability index : all the values are beneath the mean value except in the case of the Bay of Brest which corresponds to a Bay Contract, planning document contracted between the State and the Urban Community of Brest since a couple of years, and which already experienced some changes in its objectives prioritisation. Some constraints lie with the lack of funding capacity in order to ensure a continuum during and after the project, lack of ICM training for practitioners and stakeholders involved, and limited capacity in exchanging experiences and know-how with other initiatives in the same region or outside as it has been the case for the two European ICM programme demonstration sites (Bay of Brest, Bay of Arcachon). Sustainability of local ICM experiences will much depend on the support they can get within larger scale planning frameworks, at the regional and national levels, which do not exist yet.

\section{Conclusions}

This attempt to define ICM process indicators and confront them to local experiences is quite new in France. It allowed for the first time to identify, from what is actually happening at the local level, the strengths and weaknesses of available tools and their use or development in future ICM local strategies. In regard of the different institutional instruments at use in the coastal zone, and since the French legal framework is dominated by a long history and strong framework of spatial planning policy, lessons that can be drawn out from such assessment are particularly useful for the setting up of future regional and national strategies, as now recommended by the European Union policy on ICM.

Yet, it remains to see how such process indicators, also considered as indicators of success, can be fully integrated and systemically applied at the early stages of ICM strategies. From 
the active application of these indicators, in addition to the IOC-UNESCO guidebook already mentioned, it might be possible to unfold a "Good Practice Guide" consistent with the proposed indicators, which would be beneficial to ICM initiatives on the French coast and elsewhere.

It has been demonstrated that qualitatively measurable indicators can be perceived on an equal foot by a group of experts (even non ICM practitioners) sharing the same level of information and coming up with rather comparative results. The next step should consist on a feedback towards local practitioners and actors from the five case studies for validation of the proposed ICM indicators.

\section{References}

[1] GESAMP (1996) The contributions of science to integrated coastal management. GESAMP Reports and Studies No 61.

[2] Olsen S. Assessing Progress towards the goals of coastal Management. Draft Background Paper 4. Block Island Workshop on Across Portfolio Learning, May 22-24, 2001

[3] ETC-WTR (2001) EEA-Marine Conventions joint workshop on indicators. Inter-regional forum report. European Topic Center on Water under contract to the European Environement Agency.

[4] Henocque Y., Denis J. A methodological guide : steps and tools towards integrated coastal area management. IOC Manuals and Guides No 42. UNESCO 


\section{ANNEX 1 : Description and content of indices and indicators}

\section{$\underline{\text { Step } 1}$}

Relevance Index (Stakes / Objectives)

Relevance index is calculated from the mean value of the four following indicators (1 to 3 ) :

. Context preliminary identification

- Was there a preliminary identification of the general context in terms of population, society trends, economic activities, public policies (sectoral, environmental, spatial planning), legislation and institutional mechanisms ?

- Is there a well identifiable "pioneer” group at the start of the process ?

. Main issues identification

- Has an assessment (environment, socio-economy) of knowledge, main issues, involved actors and responses made (users traditional management practices and sectoral policies from the State) been carried out on the area ?

- Has an inventory of available capacity (human, institutional, financial), that can be mobilized on the short term, been made in order to consequently adjust the project scope ?

- Has the political will of decision makers been assessed ?

- Has the socio-environmental diagnostic been validated by the stakeholders ?

- Are issues prioritised ?

. Definition of the area (territory)

- Was there an accurate definition of the area geographical boundaries ?

- Does this delimitation look realistic in regard of the administrative boundaries, the main ecosystems involved and the issues which have been identified ?

- Are the seaward and landward parts sufficiently represented within the delimitated area?

. Objectives accuracy

- Was there a clear identification of stakes (environment, land-use, accidental events, socio-economic interests), strategic (goals) and operational objectives ?

- Do the defined stakes and objectives look accurate and did they change with time?

- Are objectives prioritised and have they been agreed as such by stakeholders ?

\section{Outcomes Index (Results / Products)}

The Outcomes Index corresponds to orders of results I, II and III (Olsen, 2001). The order is mentioned without comment when mostly achieved and qualified "partly" when partially achieved. When it is the case, the results may cover products like a Bay Contract, an SMVM, a Charter, etc.

\section{Order I results}

- Policy and coastal management action plan adopted

- Formalized institutional structures

- Constituencies present at local and national levels

- Official involvement and funding secured

\section{Order II results}

- Changes in behavior of institutions and stakeholders groups

- Changes in management practices from each users group

- Concrete actions implemented 


\section{Order III results}

- Investments on infrastructures and technology

- Environmental improvements

- Socio-economic improvements (quality of life, wellbeing, welfare...)

\section{Prospective Index (Scenario / Change)}

This indicator purpose is to indicate if the current process can potentially, as it is, open the way to integrated coastal management practices. The weaker the index the more necessary it is to change the current dynamic and strategy in order to pursue the goal of integrated coastal management.

\section{$\underline{\text { Step } 2}$}

Step 2 corresponds to a more in depth explanation of the previous indices values.

\section{Actors and institutional arrangements index}

The index value is equal to the mean value coming out from the following four indicators. Maximum value is 3 .

\section{. Identification of stakeholders groups}

- Are all the stakeholders groups been identified, taking into account their relative position in regard of the issues at stake?

. Assessment of political will and spheres of influence of the actors involved

- Are the vested interests, the conflicts (real or potential), the forces of resistance or potential changes, well known enough ? Have the varied political wills, underpinned by decision-makers interest, been assessed and asked at all the decision levels (from local to national) ?

. Communication efficiency

- Whatever the technical means (hardware/software tools, feedback support, etc.) utilized, is the communication of information to the different users groups sufficient and susceptible to develop a sense of ownership ?

\section{. Institutional arrangements}

- Are the different institutional arrangements which go along the ICM process enough operational and achknowledged (legitimate and legal) by stakeholders and decision-makers ?

- $\quad$ Are they supported (facilitated) by legitimate leaders ?

\section{Use and integration of tools index}

The index value is equal to the mean value of the following four indicators. Maximum value is 3 .

\section{. Social observation and engineering}

- $\quad$ The information to be gathered is not only environmental. It may also concern all aspects of the population's heritage : local structure, lifestyle, institutions, socio-economic activities, customs, practices, the local history, architecture, and so on. Usually, the corresponding data is collected via an approach incorporating interviews and surveys. The purpose of the questionnaire is to survey the activities of the main groups of actors concerned, their management styles, open or potential conflicts, and their vision of the issues. The social observation tools understand the social scene as an interplay of different 
groups and interests, where different rationales and priorities are in conflict. In the next phase, social engineering is a set of prescriptive and instrumental practices which aim to shed light on the social actors' aptitude to adapt, resist, or innovate in response to environmental problems. To what extent this approach has been applied ?

. Institutional and legal analysis

- Were there an inventory and analysis of existing laws and rules and their level of efficiency in the framework of sectoral institutional mechanisms, from the national to the local levels ?

- Did the chosen institutional tools precede the discussion or were they the nature of the discussion and the issues identified on a specific territory which determine the choice of the institutional tool ?

. Assessment and economic incentives

- Beyond the different sectors statistical results, has the ecosystem value assessment been utilized, especially for feeding the negociation and choice of options between actors during the prospective phase ?

- Have local economic incentives (taxes, grants, etc.) been used or improved for implementation of actions?

. Environmental assessment

- Did the environmental assessment allow to go beyond the sectoral approaches and consider the cross-cutting issues on the use of the area ? Were the consequent objectives enough clear and operational ?

\section{Information and communiaction index}

The index value is equal to the mean value of the four following indicators. Maximum value is 3 .

. Inventory, collecting and organisation of databanks

- Has the pre-existing information taken into account, in what fields (ecology, sociology, economy, history, policy...) ?

- Were complementary acquisition, archiving and treatment of data necessary ?

- Is there an information system which is useful and accessible to the different stakeholders involved?

- Was there a public feedback and validation of the environmental assessment or other results from specific studies ?

. Zoning

- While preparing the management plan, did you proceed to the area zoning which is not only related to uses regulation but also to the stakes and objectives corresponding to each geographic unit?

- Was this zoning validated by the different groups of actors ?

- Is the zoning coherent with the ones already existing, within and outside the territory?

. Setting up and running of the information system

- What is the information system level of development or achievement and is it operational ?

- Does it facilitate the exchanges of information with other projects?

. Information release

- Is the information easily accessible and understandable for users and is it released periodically towards the public? 


\section{Follow-up and evaluation index}

The index value is equal to the mean value of the four following indicators. Maximum value is 3.

. Indicators system

- Are indicators been defined for the follow-up of the project : D-P-S-I-R type of indicators, project performance or process indicators, etc. ? Are they organised as a management board?

- Are there monitoring networks for waters and ecosystems quality status and trends assessment ? Are they coordinated?

. Adaptation mechanisms

- To adapt to new situations (indicators evolution or stakeholders opinion), are there specific mechanisms?

. Evaluation practice

- Is self-evaluation a normal practice ? Was any external evaluation ever made . Available funding on the project?

- Are financial means sufficient in regard of the objectives ? What are the funding sources and how does it work?

- Is there any form of public-private partnership ?

\section{Adaptation and sustainability index}

The index value is eaqual to the mean value of the five following indicators. Maximum value is 3.

. Funding capacity

- Beyond proper funding of the project, have specific mechanisms for autofinancing been identify and implement?

. Training capacity

- Are training activities part of the project ? Are there educational activities at schools and specific training for stakeholders?

- Exchange of experience

- Is there any exchange of experience with other projects within the region and

. Achieved adjustments outside, informally or through networks?

- Based on results, new constraints or externalities, have any adjustment of strategy or objectives been made ?

. Legislative and institutional aspects

- $\quad$ Do the legislative and institutional frameworks allow these adjustments ? 